\title{
The safety situation within the context of simulations of crisis management processes
}

\author{
L. Malerova, K. Chmelikova \& M. Zajic \\ Department of Civil Protection, Faculty of Safety Engineering, \\ VSB-Technical University of Ostrava, Czech Republic
}

\begin{abstract}
The paper describes the design of the system of lifelong education in crisis management for persons included in a rescue system and public authorities to use simulations of crisis management. This tool will enable the preparation to be performed under conditions maximally similar to those of a real situation, including psychological and time factors. The proposed system of lifelong education is divided into modules. The present text brings the module "Protection" - teaching part of the project. This part is focused on the safety situation and the level of risk in the area. It shows the proposed method for assessing the level of risk in the area.

Keywords: crisis management, educational process, protection.
\end{abstract}

\section{Introduction}

In 2010, the Faculty of Safety Engineering, VSB-Technical University of Ostrava obtained a project within the Security research of the Czech Republic. This project is called "Simulation of crisis management processes in the system of lifelong education of integrated rescue system units and public administration bodies" (the SIMPROKIM).

The aim of the project is to design a system of lifelong education in crisis management for employees working in the rescue system units and public administration bodies. These employees are divided into crisis management groups and other bodies involved in crisis management in the territorial unit. The educational process is based on the assumption that these employees are expected to have knowledge of security issues of the territory. The educational process will be implemented using a simulation of crisis management in 
conditions similar to real life conditions, including psychological and temporal aspects [4].

Crisis management is an important tool in providing assistance to the public during emergencies. A two-stage crisis management model was selected for the needs of this project: the Protection module and the Response module that are graphically illustrated in Figure 1. Note: EE is an extraordinary event.

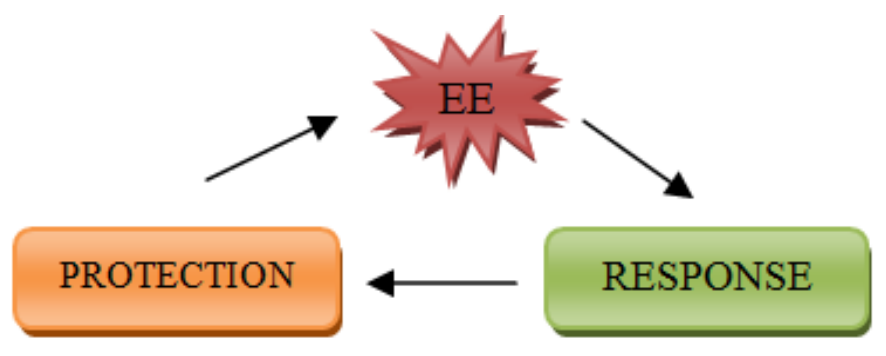

Figure 1: Basic modules [4].

Each module is defined by a knowledge base and set of skills that a participant of the project should obtain during the educational process. The "Protection" module includes a complex of activities executed during the preparation for emergency. Generally, it covers identification of possible emergencies in the area, assessing their risks, reducing the effects of emergencies and emergency preparedness. The "Response" module in general includes a complex of activities needed for dealing with the consequences of emergencies that occur in the territory [1].

The educational process in both modules operates in three stages: teaching, training and testing (Figure 2).
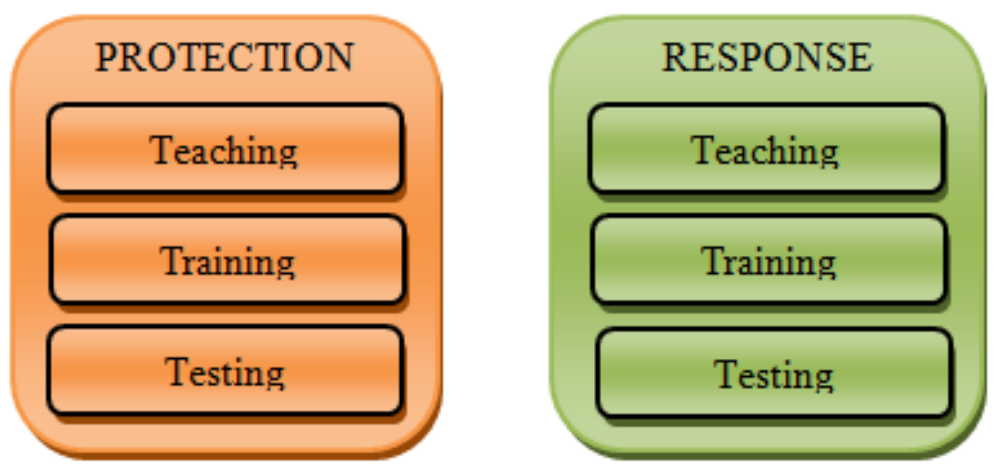

Figure 2: Basic modules - individual phases [4].

The "teaching" phase will be executed in the form of guided lectures that cover theoretical interpretation of the individual modules. The "training" phase 
includes testing the skills obtained by participants in the "teaching" phase. The "testing" phase will include validation of skills obtained in previous phases [1-4].

\section{The protection module}

Currently, the project is in phase of analysis module "Protection". The on-going phase concentrates to create a set of "teaching" texts for the course participants. The objective is to introduce and teach participants to assess the safety situation in the territory. These knowledge and skills should be applied in the preparation of the decision of the leader crisis staff.

The safety situation is characterized by achieved level of safety preparedness of territory.

The assessment of the safety situation comprises:

- $\quad$ evaluation of current information about the status of the territory from map data, based on the characteristics of the territory,

- evaluation of information on the status from the safety documentation about the territory,

- evaluation of information on the status from the safety documentation about the territory,

- $\quad$ assessment of knowledge of the current situation in the area containing the existing security documentation and

- presentation of differences between the actual condition of area and consideration and documentation.

Evaluation of the current safety situation is done for two reasons. The first is the need to improve the existing situation and the second the necessity of preparing a response to any incident in the area. In the first case, the trained persons are placed in the workplace of crisis management with the task to prepare documentation for updating the safety situation. In the second case they are in the roles of persons included in crisis staff (especially in the group of analysis in the permanent working group crisis staff) $[5,6]$.

The safety level of territory depends on the level of risk. The monitored parameters include measures: protection of the population, infrastructure and the environment, taking into account the possible occurrence of incidents within a defined territory (Figure 3).

The safety situation presents immediate state of territory, which is characterized by an objectively existing entities and relationships between them. They can either help or hinder the occurrence of extraordinary event and also determine their scope and possible consequences. On this basis, we talk about aspects of threat, vulnerability and emergency preparedness $[1,5,6]$. 
neighborhood

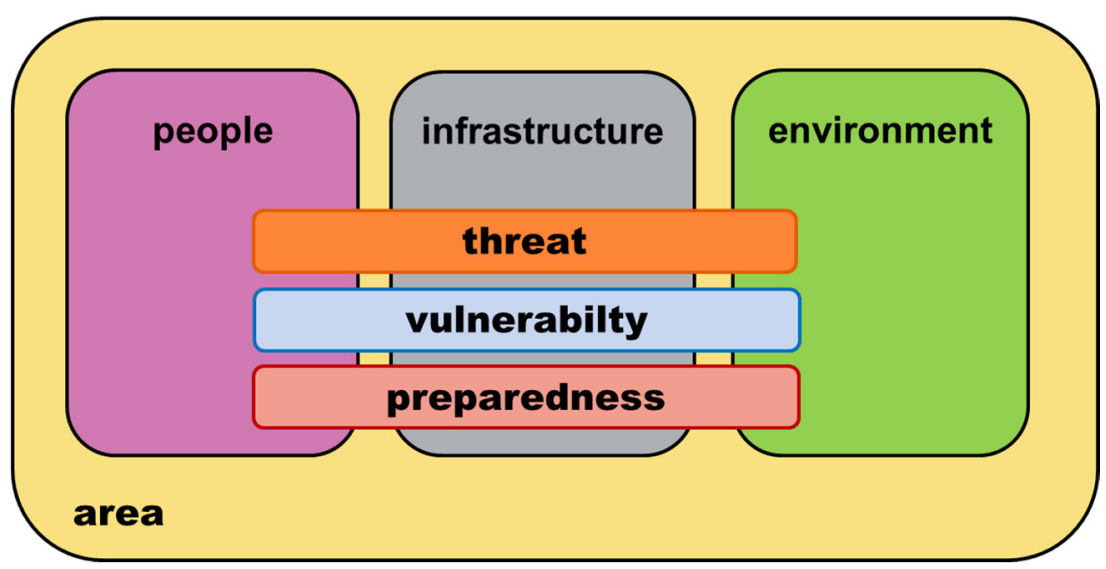

Figure 3: $\quad$ Parameters in the area $[5,6]$.

\section{Methods}

The proposed method is based on the estimate the index determination by the categorization of events, including the effect of possible subsequent emergencies. It sets the level of risk for comparing different types of extraordinary events in the studied area.

The philosophy of the proposed method is based on the target user, "informed layman". It is the person who is moving in the territory, but in terms of risk analysis is not an expert, such as a mayor, assistant emergency management or members of the standing working group.

Determination of indexes in individual analysis is made on the basis of screening existing indexes in the methods used in Czech and foreign methods. Indexes are determined for each type of extraordinary event with no consideration of the potential arising of subsequent emergencies. For the evaluation index is used five-point scale, i.e. 1 to 5 . Individual results of the analysis shall be rounded up. For the numerical evaluation of indexes for individual analyses a linear scale was chosen for its uniformity, the same weight and acceptance for user and for informed layman as well. For the purpose of the method was chosen semi-quantitative risk analysis as a compromise between the need for accuracy and difficulty of obtaining all the necessary data [6].

The procedure of the proposed method is based on a general model of risk management (Figure 4).

The first step of risk assessment is to define the area and to identify extraordinary event that may occur on the territory. Characteristics of the area consist of information about the geography, demographics, climate, infrastructure, safety important objects and economy [6].

The risk level is determined from the analysis of threat, vulnerability and preparedness, i.e. multiple of individual analyzes (formula (1)) [6]. 


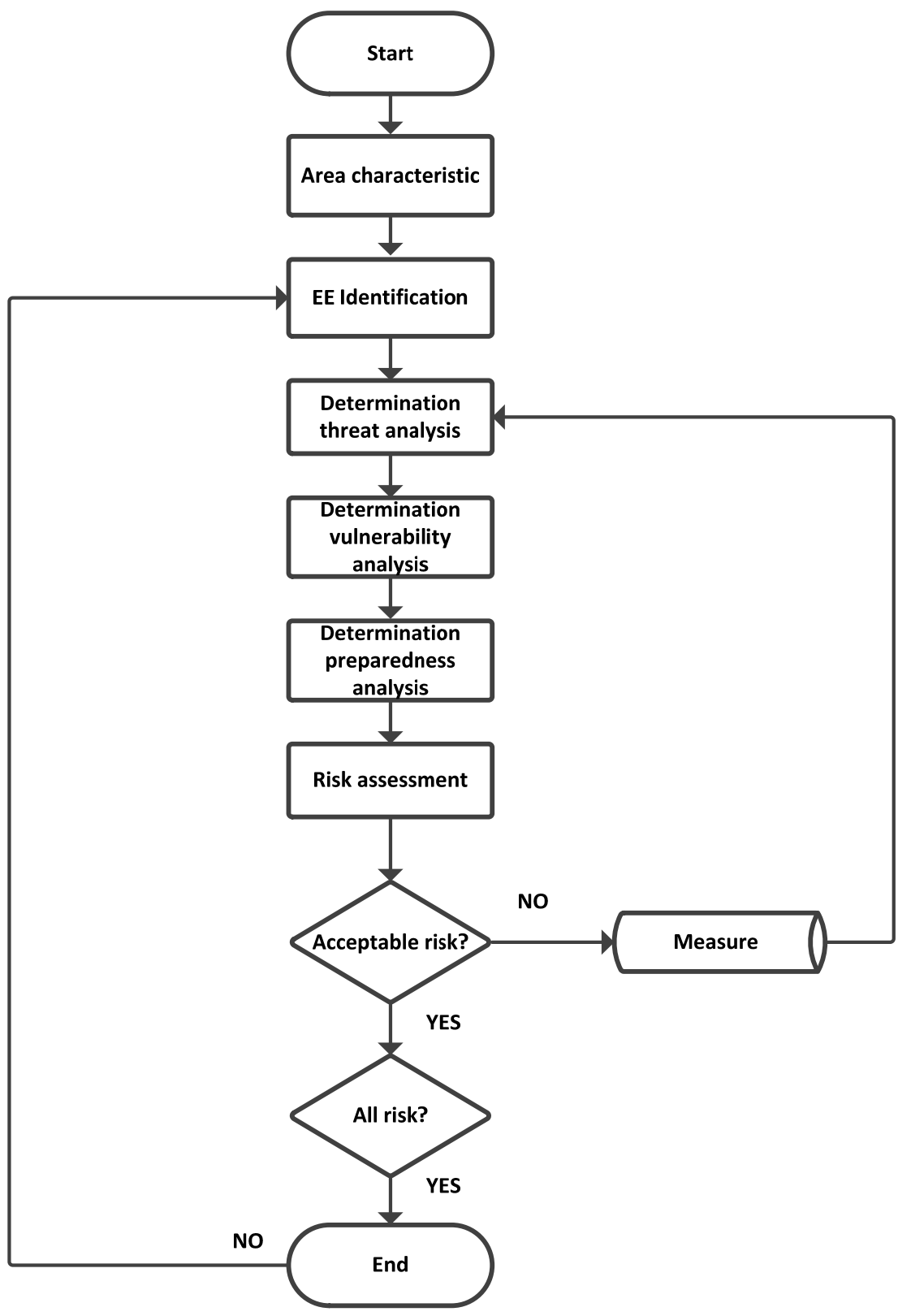

Figure 4: $\quad$ Procedure of the proposed method [6]. 


$$
R=f(A O, A Z, A P)
$$

There is:

$\mathrm{R} \quad$ level of risk

$\mathrm{AO} \quad$ threat analysis of area

AZ vulnerability analysis of area

AP preparedness analysis of area of extraordinary event

\section{Threat analysis}

Threat analysis includes determination the frequency of occurrence of potential extraordinary event and determination the extent of the impact of potential extraordinary event. For work occurrence of incidents is divided into two groups. The first group captures the incidents with "daily", or high occurrence, i.e. the frequency of their occurrence is more than 5 times per year. The second group consists of incidents with other or low occurrence, i.e. a frequency is less than 1 per two or more years (table 1). The impact of the extraordinary event is determined based on the percentage of the entire contact area [6].

Table 1: $\quad$ Summary of extraordinary event in area [6].

\begin{tabular}{|l|l|}
\hline \multicolumn{1}{|c|}{ Events with a "daily" occurrence } & Events with "another" occurrence \\
\hline $\begin{array}{l}\text { events caused by to adverse weather } \\
\text { (a) }\end{array}$ & disruption of electricity supply (f) \\
- (a1) floods & \\
- (a2) heavy snowfall & \\
- (a3) storm & \\
- (a4) prolonged drought & \\
\hline fire (b) & disruption of gas supply (g) \\
\hline $\begin{array}{l}\text { operational and technical character } \\
\text { events (c) }\end{array}$ & disruption of the supply of drinking \\
\hline traffic accident (d) & water (h) \\
\hline disruption of public order (e) & disruption in the Municipality (i) \\
\hline
\end{tabular}

\section{Vulnerability analysis}

Vulnerability analysis is determined on the basis of indexes: the population living in the area (according to the number of inhabitants in the territory and the building/area. Index of vulnerability of the population is assigned based on the total population of the area [6].

The vulnerability of the objects of the impact of risk is determined taking into account the existence of safety relevant objects/areas in this territorial unit. Objects are considered from two perspectives, whether the operation of the 
building effect of increasing risk - objects R (Risk) or its reduction - objects $\mathrm{S}$ (Safety). The vulnerability of the territory will therefore depend on the number of these objects. For the purpose of the method were chosen the following types of objects $[6,7]$ :

- Multi-storey residential buildings

- Objects of civic amenities

- Objects for production

- Objects for agriculture

- Other objects

In the case that in the territory there are multi-storey residential buildings, amenity buildings and industrial facilities, their number is multiplied by 2 . The reason for choosing higher coefficient is occupancy of objects. It is an object with a larger number of gathering people (according to the availability of shifts: permanently, temporarily occupied by persons), when these objects become more vulnerable [6].

\section{Preparedness analysis}

Preparedness analysis has two important components - the ability to response and recovery capability relating with urgent responses in the event of an emergency. Urgent response aims to maintain the functionality of the risk element and as quickly as possible to restore functionality [6].

The very concept of preparedness, which for the purposes of the method is the ability to territorial security system, it means:

- maintain the reaction, the ability of human, material and other resources and territories for their disposal

- create conditions for the recovery of areas affected by the consequences of the incident

Responsiveness represents time horizon, when the longer is the response capabilities, the greater is the impact on the area.

Index responsiveness includes areas:

- warning the population

- availability of components of the Integrated Rescue System (next IRS)

Warning is a warning informing the population and is done based on of sirens (sirens types), local radio and websites.

Availability of IRS components is defined as the distance (number $\mathrm{km}$ ) of the nearest point of application (fire station, exit the base, service) of basic components of the IRS (Fire Rescue, Emergency Medical Services, Police) for the case to request their use [6]. 
Recovery capability ensures the return and estimates the time required for recovery of the area damaged by incident into stable state. This is an immediate recovery [6].

\section{Software}

For the purpose of the project was made program, which relies on safety issues. Currently, a simple software version is based on issues with a perspective to GIS. For the purposes was chosen programming language Java for its widespread use. The program is divided into questions by analysis of threats, vulnerabilities and preparedness.

The program include in box menu: information about the methodology, terminology and printing results. The results are visualized in the table. This table contains determination of the three individual analyzes and the resulting risk. Scale level of risk was based on the subjective impression of project experts [6].

Note: The application is in Czech language. For the purposes of this article program was modified and shortened (Figure 5).

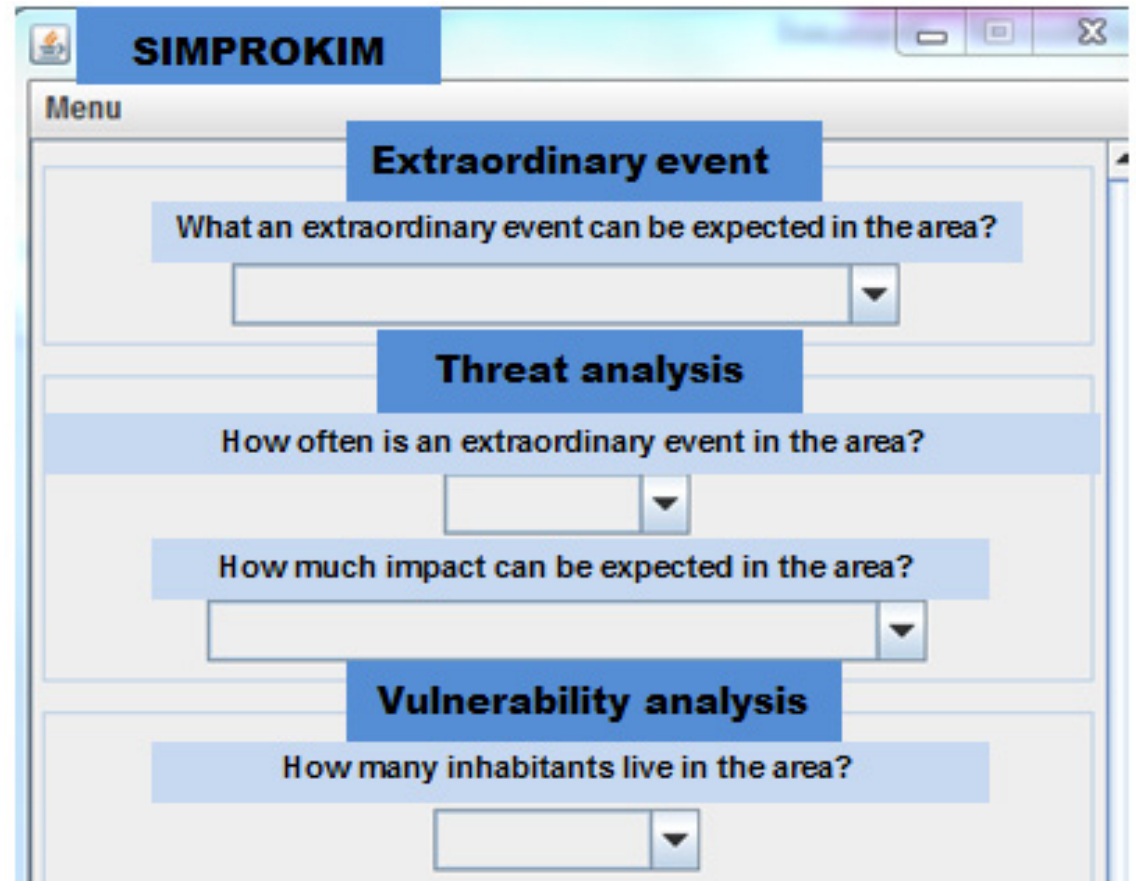

Figure 5: $\quad$ Software for assessment risk in area $[2,6]$.

Table 2 describes part information which is used in the software for assessment in the area. 
Table 2: Describe of information in software for assessment risk in area [6].

\begin{tabular}{|c|c|c|c|}
\hline Field & Question & Answer & Scale \\
\hline $\begin{array}{l}\text { Extraordinary } \\
\text { event }\end{array}$ & $\begin{array}{l}\text { What } \\
\text { extraordinary } \\
\text { event can be } \\
\text { expected in the } \\
\text { area? }\end{array}$ & $\begin{array}{l}\text { Extraordinary events are } \\
\text { described in Table } 1\end{array}$ & Without \\
\hline Threat analysis & $\begin{array}{l}\text { How often is } \\
\text { there an } \\
\text { extraordinary } \\
\text { event in the } \\
\text { area? }\end{array}$ & $\begin{array}{l}\text { - } 1 \mathrm{x} \text { in } 300 \text { years } \\
\text { - } 1 \text { in } 100 \text { years } \\
\text { - } 1 \text { in } 30 \text { years } \\
\text { - } 1 \text { in } 10 \text { years } \\
\text { - } 1 x \text { per year }\end{array}$ & $\begin{array}{l}1 \\
2 \\
3 \\
4 \\
5\end{array}$ \\
\hline $\begin{array}{l}\text { Vulnerability } \\
\text { analysis }\end{array}$ & $\begin{array}{l}\text { How many } \\
\text { inhabitants live } \\
\text { in the area? }\end{array}$ & $\begin{array}{ll}\text { - } & \text { within } 200 \\
\text { - } & \text { from } 201 \text { to } 1000 \\
\text { - } & \text { from } 1001 \text { to } 5000 \\
\text { - } & \text { from } 5001 \text { to } 50000 \\
\text { - } & \text { over } 50000\end{array}$ & $\begin{array}{l}1 \\
2 \\
3 \\
4 \\
5\end{array}$ \\
\hline
\end{tabular}

\section{Conclusion}

The paper shows the SIMPROKIM project, which focuses on training in crisis management for persons active in the emergency services and public administration bodies, included in crisis staffs and other bodies operating in crisis management territorial unit. In an interactive learning system in the module "Protection-teaching" (hereinafter Protection), participants will learn safety problems in the territory. Each phase module "Protection" will include the theory of crisis management with a focus on familiarization, assessment and creation of the security situation in the study area, which will serve to Crisis Staff in response to the situation. Part of the article is capturing the proposed method for assessing the level of risk in the territory. The level of safety depends on the level of risk. The article shows the proposed method for the determination of level of risk in the territory with the possibility of using the software.

\section{Acknowledgements}

This study was supported by the Research plan No.VG20102015043 "Simulation of crisis management processes in system of lifelong learning of participant Integrated Rescue System and public services", which is financed by the Ministry of interior of the Czech Republic. (Security Research for the Needs of the State 2010-2015 (2010-2015)). 


\section{References}

[1] Adamec, V., A study to assess the level of civil emergency preparedness territorial units, habilitation thesis, VSB-Technical University of Ostrava, Faculty of Safety Engineering. Ostrava. 104 p, 2008.

[2] Drozdova, M., Rapant, P., Malerova, L., Support system for training of crisis management group members, Safety and Security Engineering V, SAFE 2013, Roma, ISBN: 978-1-84564-744-5, 247-256 p.

[3] Green, L. V., Kolesar, P. J., Improving emergency responsiveness with management science. Management Science, New York. 2004, Vol. 50, No. 8, pp. 1001-1014. ISSN: 00251909.

[4] Hrdina, P., Malerova, L., Simulation of crisis management processes as a means of education, In: Transactions of the VŠB-Technical University of Ostrava, Safety Engineering Series, Number 1, 2012, Volume VII, 2012.73 -76 p. ISSN 1801-1764.

[5] Malerova, L. Crisis management and simulation of processes as education tool, In International Interdisciplinary Scientific Conference of PhD students and lecturers QUAERE 2013. Hradec Kralove: MAGNANIMITAS, 3. publication. 2013. ISBN 978-80-905243-7-8, ETTN 085-13-13020-05-1.

[6] Malerova, L., Risk analysis of are, dissertation thesis, VSB-Technical University of Ostrava, Faculty of Safety Engineering. Ostrava, 93 p, 2014.

[7] Zajic, M., Adamec, V., Application of risk analysis in security protection objects, In: Proceedings of the Conference of Civil Protection, Ostrava 2012, ISBN: 978-80-7385-109-5, ISSN: 1803-7372. 